\title{
Coexpression of VEGF-C and COX-2 and its association with lymphangiogenesis in human breast cancer
} Xiao-Hua Zhang1, Du-Ping Huang*1, Gui-Long Guo', Guo-Rong Chen², HuXiang Zhang2, Li Wan ${ }^{2}$ and Sheng-Ying Chen ${ }^{3}$

\author{
Address: ${ }^{1}$ Department of Oncology, The First Affiliated Hospital of Wenzhou Medical College, Wenzhou, 325000, China, ${ }^{2}$ Department of \\ Pathology, The First Affiliated Hospital of Wenzhou Medical College, Wenzhou, 325000, China and ${ }^{3}$ Department of stomatology, The First \\ Affiliated Hospital of Wenzhou Medical College, Wenzhou, 325000, China \\ Email: Xiao-Hua Zhang - oncology0607@yahoo.com.cn; Du-Ping Huang* - oncology0607@yahoo.com.cn; Gui- \\ Long Guo - oncology2004@163.com; Guo-Rong Chen - glchen2007@yahoo.com.cn; Hu-Xiang Zhang - hxzhang1234@yahoo.com.cn; \\ Li Wan - wanli@yahoo.com.cn; Sheng-Ying Chen - csyo62@yahoo.com.cn \\ * Corresponding author
}

Published: 13 january 2008

BMC Cancer 2008, 8:4 doi:10.1/86/147I-2407-8-4

This article is available from: http://www.biomedcentral.com/I47/-2407/8/4

(C) 2008 Zhang et al; licensee BioMed Central Ltd.

This is an Open Access article distributed under the terms of the Creative Commons Attribution License (http://creativecommons.org/licenses/by/2.0), which permits unrestricted use, distribution, and reproduction in any medium, provided the original work is properly cited.
Received: 20 December 2006

Accepted: 13 January 2008

\begin{abstract}
Background: Lymphangiogenesis has become a new research frontier in tumor metastasis since the discovery of reliable lymphatic markers that have allowed observation and isolation of lymphatic endothelium. Cyclooxygenase-2 (COX-2) has been reported to be involved in the critical steps in carcinogenesis. However, possible role of COX-2 in lymphangiogenesis and lymphatic metastasis is still poorly understood. In present study, we aimed to investigate the relationship between vascular endothelial growth factor-C (VEGF-C) and COX-2 in human breast cancer, and correlations with lymphangiogenesis and prognosis.
\end{abstract}

Methods: Tissue samples of primary tumors from 70 patients undergoing intentionally curative surgical resections for breast cancer were immunohistochemically examined for VEGF-C, COX-2, and D2-40 expressions. The association between COX-2 and VEGF-C expressions and clinicopathological parameters as well as prognosis were analysised. To demonstrate the presence of proliferating lymphatic endothelial cells, 10 random cases with high LVD counts were selected for D2-40/Ki-67 double immunostaining.

Results: A significant correlation was found between the expression of VEGF-C and COX-2 $(r=$ $0.529, P<0.001$ ), and both elevated VEGF-C expression and elevated COX-2 expression were associated with higher lymph vessel density (LVD), lymph node metastasis and D2-40 positive lymphatic invasion (LVI) as well as worse disease free survival (DFS) and overall survival (OS) in a univariate analysis. In the double immunostain for the lymph vessel marker D2-40 and the proliferation marker Ki-67, the results confirmed Ki-67-positive nuclei in a proportion of lymph vessel endothelial cells.

Conclusion: There is indeed lymphangiogenesis in breast cancer, the most compelling evidence being the presence of proliferating lymphatic endothelial cells. VEGF-C and COX-2 are coexpressed and significantly associated with lymphangiogenesis and prognosis in invasive breast cancer. Suggesting COX-2 may up-regulate VEGF-C expression and thus promote lymph node metastasis via lymphangiogenesis pathway in human breast cancer. 


\section{Background}

The lymphatic vasculature is an important route for the metastatic spread of human cancer. And the presence of tumour foci in lymph nodes is the most important adverse prognostic factor in a variety of human cancers. Recently, lymphangiogenesis, the formation of new lymphatic vessels, has become a new research frontier in tumor metastasis since the discovery of the two major lymphatic vessel growth factors-C (VEGF-C) and -D (VEGF-D), as well as reliable lymphatic markers that have allowed observation and isolation of lymphatic endothelium[1]. VEGF-C, a member of the VEGF family, has been shown to promote tumour lymphangiogenesis, the spreading of tumour cells to lymph nodes in various animal models of cancer[2,3]. Furthermore, the elevation of VEGF-C appears to correlate with lymph node metastasis in numerous human cancers including breast cancer [4].

Cyclooxygenase-2 (COX-2), the inducible isoform of prostaglandin $\mathrm{H}$ synthase, has been reported to be significantly overexpressed in a variety of human malignancies including breast cancer, and was identified to be involved in the critical steps in carcinogenesis [5-7]. However, possible role of COX-2 in lymphangiogenesis and lymphatic metastasis is still poorly understood. Recently, it was reported that COX-2 up-regulated VEGF-C and promotes lymphangiogenesis in human lung adenocarcinoma[8] and oesophageal adenocarcinoma $[9,10]$ as well as in the head and neck [11]. However, data is still scarce in breast cancer and it is necessary to provide more documents to increase the dataset.

In present study, we aimed to investigate the role of COX2 immunohistochemical expression in lymphangiogenesis, VEGF-C expression and D2-40 positive lymphatic vessel invasion (LVI) as well as prognosis in a series of archival human invasive breast cancer samples.

\section{Methods}

\section{Patients and specimens}

Paraffin-embedded archival specimens from 70 patients with unilateral, invasive breast cancer, who were diagnosed and treated in the Department of Oncology, The First Affiliated Hospital of Wenzhou Medical College, from Januanry 2000 to October 2001, were included in the study. We excluded patients with in situ carcinoma, distant metastases at the time of the diagnosis, synchronous or metachronous bilateral breast cancer, malignancy other than breast cancer in history, and the patients who had received neoadjuvant chemotherapy or radiation therapy before surgery, which left 70 patients for the analysis. All patients had received mastectomy with dissection of axillary lymph nodes, containing at least 10 nodes.
Routine histological examination was performed with hematoxylin-eosin staining. All carcinomas were classified in accordance with the criteria of the World Health Organization and were recorded as invasive ductal or invasive lobular as well as invasive medullary-like carcinomas. The combined histological grade was obtained according to a modified Scarff-Bloom-Richardson histological grading system with guidelines as suggested by Nottingham City Hospital pathologists [12]. Tumor size and lymph node status were evaluated separately. The clinicopathological characteristics of the series are shown in Table 1.

\section{Immunohistochemistry}

Sections ( $4 \mathrm{um}$ ) of paraffin-embedded tissue block were rehydrated by sequential immersion in xylene, graded ethanol and water, and then they were incubated in 3\% hydrogen peroxide methanol for $5 \mathrm{~min}$, and followed by using a microwave oven for antigen retrieval. After washing in phosphate-buffered saline (PBS), the slides were exposure to $10 \%$ normal goat serum for $10 \mathrm{~min}$ to reduce non-specific binding, this was followed by an overnight incubation at $4^{\circ} \mathrm{C}$ in a humidified chamber with polyclonal rabbit antihuman VEGF-C antibody (Zymed, USA) at 1:100 dilution, and monoclonal mouse antihuman COX2 antibody (Zymed, USA) at 1:100 dilution. The antigenantibody reaction was visualized by Picture Plus Kit (Zymed, USA) and diaminobenzidine as the chromogen. Finally, hematoxylin was used as a counterstain. Negative controls were processed as above except for the primary antibodies were used. Sections of colon cancer known to express COX-2 and VEGF-C were used as positive controls.

A monoclonal mouse antihuman D2-40 antibody (Zymed, USA) was used for the staining of lymphatic vessels. The procedure of immunohistochemical staining of D2-40 is similar to that of the COX-2 and VEGF-C staining at a dilution of 1:100. And section from previously studied case of tonsilla known to express D2-40 was used as the positive control.

To demonstrate the presence of proliferating lymphatic endothelial cells, 10 random cases with high LVD counts (above 50 percentile) were selected for D2-40/Ki-67 double immunostaining. First, a monoclonal antibody directed at Ki-67 (DakoCytomation; dilution 1:150) was applied to the rehydrated paraffin sections for 30 minutes after antigen retrieval in citrate buffer ( $\mathrm{pH} 6.0)$ at $98^{\circ} \mathrm{C}$. Sections were incubated with EnVision+ Dual Link solution before development with diaminobenzidine (DakoCytomation). Sections were then stained with the D2-40 antibody (Zymed; dilution 1:20) for 60 minutes. EnVision System alkaline phosphatase and Fast Red chromogen (DakoCytomation) were used to visualize binding of this second antibody. 
Table I: Correlation of clinicopathologic parameters with VEGF-C and COX-2 expressions.

\begin{tabular}{|c|c|c|c|c|c|c|c|}
\hline \multirow[b]{2}{*}{ Factor } & \multirow[b]{2}{*}{ No. of cases } & \multicolumn{2}{|c|}{ VEGF-C Expression } & \multirow[b]{2}{*}{$P$ value } & \multicolumn{2}{|c|}{ COX-2 Expression } & \multirow[b]{2}{*}{$P$ value } \\
\hline & & Low & High & & Low & High & \\
\hline LVD & & $9.63 \pm 5.09$ & $12.83 \pm 5.27$ & $0.007^{a}$ & $9.17 \pm 5.07$ & $11.96 \pm 5.32$ & $0.012^{\mathrm{a}}$ \\
\hline \multicolumn{8}{|l|}{ Age } \\
\hline$\leq 50$ & 40 & 23 & 17 & 0.944 & 12 & 28 & 0.383 \\
\hline$>50$ & 30 & 17 & 13 & & 12 & 18 & \\
\hline \multicolumn{8}{|l|}{ Tumor size } \\
\hline$\leq 2$ & 28 & 18 & 10 & 0.324 & 10 & 18 & 0.837 \\
\hline$>2$ & 42 & 22 & 20 & & 14 & 28 & \\
\hline \multicolumn{8}{|c|}{ Hisyological grade } \\
\hline $\mathrm{G} 1$ and $\mathrm{G} 2$ & 41 & 31 & 10 & $<0.001$ & 17 & 24 & 0.132 \\
\hline G3 & 29 & 9 & 20 & & 7 & 22 & \\
\hline \multicolumn{8}{|c|}{ Lymph node metastasis } \\
\hline Positive & 32 & 13 & 19 & 0.010 & 6 & 26 & 0.012 \\
\hline Negative & 38 & 27 & 11 & & 18 & 20 & \\
\hline \multicolumn{8}{|l|}{ Histology } \\
\hline IDS, NOS & 59 & 32 & 27 & 0.420 & 19 & 40 & 0.614 \\
\hline Others & 11 & 8 & 3 & & 5 & 6 & \\
\hline \multicolumn{8}{|l|}{ ER } \\
\hline Positive & 54 & 32 & 22 & 0.511 & 22 & 32 & 0.037 \\
\hline Negative & 16 & 8 & 8 & & 2 & 14 & \\
\hline \multicolumn{8}{|l|}{ PR } \\
\hline Positive & 46 & 27 & 19 & 0.716 & 19 & 27 & 0.087 \\
\hline Negative & 24 & 13 & 11 & & 5 & 19 & \\
\hline \multicolumn{8}{|l|}{ c-erbB-2 } \\
\hline Positive & 13 & 6 & 7 & 0.375 & 2 & 11 & 0.205 \\
\hline Negative & 57 & 34 & 23 & & 22 & 35 & \\
\hline \multicolumn{8}{|l|}{ LVI } \\
\hline Positive & 25 & 10 & 15 & 0.031 & 4 & 21 & 0.016 \\
\hline Negative & 45 & 30 & 15 & & 20 & 25 & \\
\hline
\end{tabular}

a Analysis by Mann-Whitney $U$ test.

\section{Evaluation of staining}

The evaluation of staining were performed by two investigators (Zhang and $\mathrm{Li}$ ), who were unaware of the clinical data or the disease outcome, examined all slides independently. When the interpretation differed between the two observers, slides were revaluated for a final decision at a conference microscope.

For VEGF-C and COX-2 assessment, determination of the intensity of the immunohistochemical staining was performed according to Su et al. [8]. The immunostained sections were scanned by light microscopy, and all of the tumor cells were evaluated: -, negative; +, focal expression $<5 \%$ of cancer tissues; ++ , focal expression in $5-20 \%$ of cancer tissues; and +++ , diffuse expression $>20 \%$ of cancer tissues. The tissue with ++ and +++ staining of COX2 or VEGF-C was classified as 'high expression group' and those with - and + staining was assigned as 'low expression group'.
Determination of lymphatic vessel density (LVD) was performed as suggested by Weidner et al.[13]. The immunostained sections were scanned by light-microscopy at low magnification $(40 \times)$ and the areas of tissue with the greatest number of distinctly highlighted microvessels ('hot spots') were selected. LVD was then determined by counting all immunostained vessels at a total magnification of $(200 \times)$ from five areas for each case.

Determination of the staining reaction was strictly confined to the 'hot spots' and the mean number of lymph vessels in each case was evaluated. LVI was considered evident if at least one tumor cell cluster was clearly visible inside the D2-40 stained vascular space [14].

\section{Statistics}

Spearman's coefficient of correlation, Chi-squared test, and Mann-Whitney test were used as appropriate. Overall survival (OS) curves and Disease free survival (DFS) curves were obtained using the Kaplan-Meier method and compared using the log-rank test. A multivariate model 
using the Cox stepwise regression analysis was used to evaluate the statistical strength of independent association between covariates and DFS and/or OS. For all tests, a $P$-value less than 0.05 was considered to be significant. All $P$-values given are results of two-sided tests.

\section{Results \\ Clinical data}

The median age at diagnosis for the 70 patients was 49 years (range, $30-77$ years). $57.1 \%(\mathrm{n}=40)$ of the patients were younger than 50 years, and $45.7 \%(n=32)$ of the patients had lymph node metastasis at the time of surgery (Table 1). Median follow-up time for the 70 subjects was 68 months (range, 28-83 months). During this observation time, 20 patients developed recurrent disease, and 15 died from their cancer.

\section{VEGF-C, COX-2 and D2-40 expression in human breast cancer tissues}

Positive staining of both VEGF-C and COX-2 proteins was seen in the cytoplasm of tumor cells (Fig 1a-b). However, occasionally, normal epithelial cells and stromal components showed faint staining, particularly adjacent stromal endothelial cells for VEGF-C. High VEGF-C expression was observed in 30 of 70 tumor samples (42.8\%), while high COX-2 expression occurred in 46 of the 70 tumor samples (65.7\%). D2-40 expression was essentially restricted to thinwalled vessel-like structures. D2-40 positive lymphatic vessels were almost exclusively found within the tumor stroma, at the tumor's invasion front (Fig 1c). Occasional invasion of the carcinoma cells into the lymph vessels was observed (Fig 1d). Median LVD was 11 microvessels/field (range, 3-26 vessels).

In the double immunostain for the lymph vessel marker D2-40 and the proliferation marker Ki-67, the evaluation of Ki-67 was performed according to Beasley et al.[15]. Positive staining of Ki-67 was seen in nuclei of lymphatic endothelial cells (Fig 1e-f, black arrows). Proliferating lymphatic endothelial cells were observed in 8 of the 10 cases analyzed. And, as expected, Ki-67-positive nuclei were observed in the tumor cells themselves.

\section{COX-2 expression correlated with VEGF-C level, lymph node metastasis and lymphatic vessel density}

As showed in Table 2, there was a significant correlation between COX-2 and VEGF-C protein expression of tumor cells $(P<0.001, r=0.529$, Spearman's coefficient of correlation).

The associations between VEGF-C and COX-2 expressions and the clinicopathologic parameters are shown in Table 1. Both high expression of the VEGF-C and COX-2 were correlated with the presence of lymph node metastasis $(P$ $=0.010, P=0.012$ respectively, both Chi-Square test) and
LVI $(P=0.031, P=0.016$ respectively, both Chi-Square test). LVD was significantly higher in patients with high expression of VEGF-C compared to patients with low expression ( $P=0.007$, Mann-Whitney test), and there was also a similar significantly association between LVD and COX-2 expression ( $P=0.012$, Mann-Whitney test). Additionly, high expression of VEGF-C, but not of COX-2 was correlated with advanced histological grading $(P<0.001$, Chi-Square test), and COX-2 expression was correlated with ER status $(P=0.037$, Chi-Square test $)$. As showed in Table 1, there was no significant association between COX-2 expression and age $(P=0.383$, Chi-Square test $)$, histological type $(P=0.614$, Chi-Square test $)$, size of primary tumor $(P=0.837$, Chi-Square test $)$, c-erbB-2 status $(P=0.205$, Chi-Square test $)$ and PR status $(P=0.087$, ChiSquare test). Furthermore, a significant association between LVI and LVD was found ( $P=0.002$, Mann-Whitney test).

\section{Survival analysis}

Kaplan-Meier curves for survival are shown in Figure 2. Patients with high expression of VEGF-C showed a significantly shorter DFS $(P=0.008$, log-rank test, Fig $2 a)$ and OS $(P=0.014$, log-rank test, Fig $2 b)$ than patients with low expression. Meanwhile, patients with high expression of COX-2 was also found to have a significantly shorter DFS $(P=0.009$, log-rank test $)$ and OS $(P=0.043$, log-rank test) than patients with low expression.

In Cox regression for DFS including patients'age, histological grading, VEGF-C expression, histological type, tumor size, LVD, lymph node metastasis, hormonal status, cerbB-2, LVI and COX-2 expression, only ER $(P=0.045)$, LVI $(P=0.025)$, c-erbB-2 status $(P=0.007)$ and LVD $(P=$ $0.015)$ remained as independent prognostic factors. However, based on multivariate Cox regression analysis for OS, only c-erbB-2 status $(P=0.028)$ and $\operatorname{LVD}(P=0.002)$ were identified as the independent prognostic factors (Table 3).

\section{Discussion}

COX-2 is a pleiotropic enzyme that mediates many physiological functions in breast cancer progression such as inhibition of cell apoptosis, increased cell motility, as well as angiogenesis [5,7]. Costa et al.[16] reported that COX2 overexpression was significantly associated with lymph node metastasis in human breast cancer. However, whether COX-2 contributes to the formation of new lymphatic vessels is still little known. In the present study, elevated COX-2 expression was positively correlated with LVD and LVI. And the expression of COX-2 protein was significantly higher in lymph node-positive group than in the node-negative group. Which may suggest COX-2 promote the formation of lymphatic vessels and lymph node metastasis. In addition, univariate analysis demonstrated 

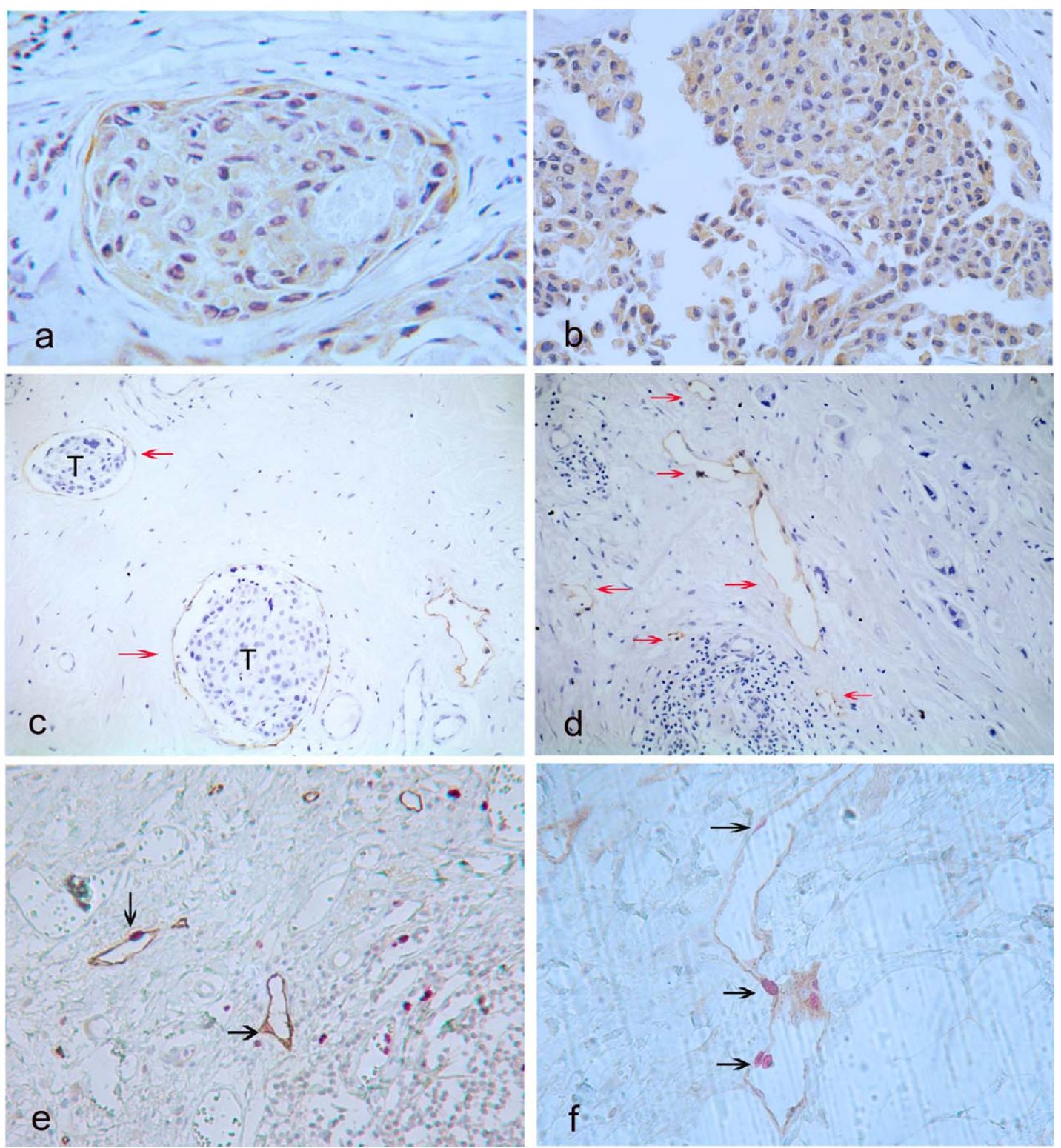

\section{Figure I}

(a) : Breast cancer specimen with high vascular endothelial growth factor-C expression. Note the typical cytoplasmatic staining reaction, original magnification 400×. (b) : Breast cancer with high cyclooxygenase-2 expression. Typically granular staining was diffuse in cytoplasm of the cancer cells, original magnification 400x. (c) : D2-40-stained lymphatic vessel (arrows) with tumor cells (T) inside (lymph vessel invasion) was noted, original magnification 200x. (d) : Breast cancer specimen with a high peritumoral lymphatic vessel density (LVD), some of the lymphatic vessels stained for D2-40 are marked with arrows, original magnification 200x. (e-f): Double staining for D2-40 (brown) and Ki-67 (red) of lymph vessels; Positive staining for Ki-67 is seen in nuclei of lymphatic endothelial cells (black arrows), original magnification $400 \times$.

that high COX-2 expression was negatively associated with both DFS and OS. The result provides an explanation that patients with high COX-2 expression were more likely to have poor prognosis than low expression patients, possibly resulting from COX-2-derived lymphangiogenesis in human breast cancer.
Research on tumor lymphangiogenesis has lagged behind that of angiogenesis because of the lack of a specific lymphatic marker and the absence of detailed knowledge concerning the molecular mechanisms of lymphangiogenesis [1]. Recently, D2-40 antibody was reported to detect a fixation-resistant epitope on a $40 \mathrm{kDa}$ O-linked sialoglyco- 
Table 2: Correlation between levels of cyclooxygenase-2 (COX-2) and vascular endothelial growth factor-C (VEGF-C) expression in human breast cancer.

\begin{tabular}{ccccc}
\hline & & & COX-2a & \\
VEGF-Ca & - & + & $2+$ & $3+b$ \\
\hline$-b$ & 4 & 6 & 4 & 1 \\
+ & 3 & 8 & 10 & 4 \\
$2+$ & 1 & 2 & 12 & 7 \\
$3+$ & 0 & 0 & 2 & 6 \\
\hline
\end{tabular}

a Detection of the expressing level of COX-2 and VEGF-C by immunohistochemistry.

b Intensity of immunohistochemical staining.

protein expressed in lymphatic endothelium but not blood vessels, and can be used to assess lymphangiogenesis specifically in conventionally processed formalinfixed and paraffin-embedded tissue specimens $[17,18]$. The present study clearly demonstrated that D2-40 reacted with the endothelium of lymphatic vessels, which
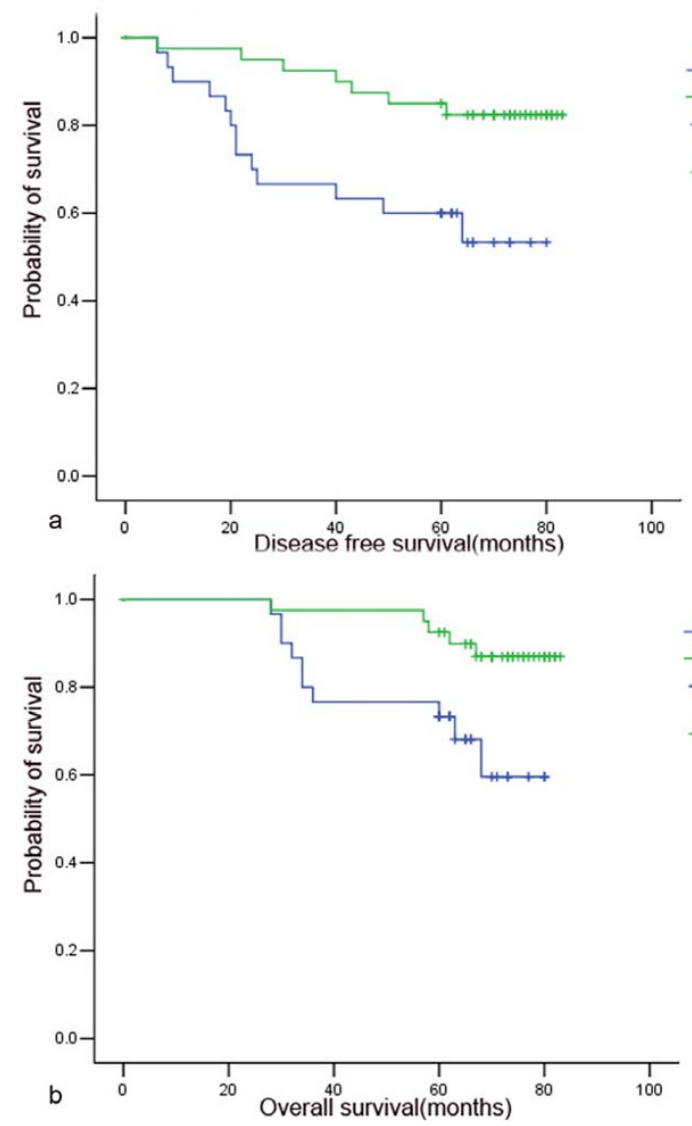

Figure 2

Association of VEGF-C expression with patients'prognosis in breast cancer (Kaplan-Meier method and log-rank test). High VEGF-C expression was significantly related to recurrence $(\mathrm{a}, P=0.008)$ and death $(\mathrm{b}, P=0.014)$. are covered with flattened endothelial cells, and does not react with endothelial cells of blood vessels. Suggesting D2-40 is a new selective marker of lymphatic endothelial cells. In this study, D2-40 immunohistochemistry revealed that lymph vessels were restricted to the endothelium, almost exclusively in peri-tumoral lesions but not in intra-tumoral lesions. Our results are consistent with previously reported studies [19-21], and might be explained by a rising interstitial pressure caused by an increase in the size of lesion or by the lack of intratumoral lymphangiogenesis in breast cancer. Indicating that peritumoural lymphatic vessels are important for the process of metastatic spread while intratumoural lymphatic vessels are nonfunctional $[21,22]$.

In the present study, we carried out double immunostaining with antibodies to D2-40 and Ki-67 to observe the occurrence of dividing nuclei among lymphatic endothelial cells. The results confirmed Ki-67-positive nuclei in a proportion of lymph vessel endothelial cells, suggesting that there is indeed lymphangiogenesis in breast cancer, the most compelling evidence being the presence of proliferating lymphatic endothelial cells.

Experimental murine tumour models have demonstrated a role for VEGF-C in tumour lymphangiogenesis and the subsequent formation of lymph node metastasis [23]. Here we show that increased VEGF-C expression was associated with lymph node metastasis, higher LVD and LVI in human breast cancer. Our results suggest VEGF-C is a potent enhancer of tumor lymphangiogenesis, leading to increased metastatic spread of breast cancer cells to lymph nodes. However, Kinoshita et al. [24] did not obtain a significant association between VEGF-C expression and lymph node metastasis. The difference between our findings and those reported by Kinoshita et al. [24] may be due to the use of different antibodies and the different number of the cases as well as evaluation method of immunohistochemistry.

In the present study, a significant association between increased VEGF-C expression and advanced histological grading was found, suggesting that poorly differentiated tumor cells may be more capable to secrete VEGF-C, which induced lymphangiogenesis in breast cancer.

The secretion of VEGF-C and VEGF-D by some tumours could induce the activation of their receptor, VEGFR-3 on the vascular endothelium and thereby inducing the formation of new lymphatic vessels. However, little is currently known about the factors that make dome tumours secret these lymphangiogenic factors [25]. In the present study, a significant positive correlation between COX-2 and VEGF-C protein expression of tumor cells was seen, which confirm to the previous studies $[8-11,26]$, suggest- 
Table 3: The multivariate Cox regression analysis for DFS and OS in 70 patients with invasive breast cancer.

\begin{tabular}{lccc}
\hline & $\begin{array}{c}\text { Significance Multivariate P } \\
\text { (Cox regression) }\end{array}$ & 95\%Confidence Interval & Hazard ratio \\
\hline $\begin{array}{l}\text { Disease-free survival } \\
\text { LVD }\end{array}$ & $0.015^{*}$ & $1.289-11.007$ & 3.766 \\
ER & $0.045^{*}$ & $0.134-0.976$ & 0.361 \\
C-erbB-2 & $0.007^{*}$ & $1.509-13.731$ & 4.552 \\
LVI & $0.025^{*}$ & $1.162-9.648$ & 3.348 \\
VEGF-C expression & 0.167 & & \\
COX-2 expression & 0.330 & & 3.452 \\
Overall survival & & $2.021-20.595$ & 3.413 \\
LVD & $0.002^{*}$ & $1.142-10.199$ & \\
C-erbB-2 & $0.028^{*}$ & & \\
VEGF-C expression & 0.155 & & \\
COX-2 expression & 0.375 & & \\
\hline
\end{tabular}

*Statistically significant (Cox regression).

ing a lymphangiogenesis pathway that COX-2 may upregulate VEGF-C expression and thus the formation of new lymphatic vessels in human breast cancer. However, the correlation is much weaker compared with the result reported by Timoshenko et al.[26] (correlation coefficients 0.553 vs 0.940 ). The discrepancy may be due to use of different methods and different number of tumors studied. For example, COX-2 and VEGF-C mRNA expression could also be observed in normal breast epithelium $[27,28]$, RT-PCR assay could not to reveal the two molecules expression exactly if microdissection was not performed, as well as the possibility that stromal cells and/or immigrant leukocytes may also be the source of both molecules except for the breast cancer cells. Recently, HIF-1a was also found to have a possible role in tumor lymphangiogenesis through the regulation of VEGF-C in human esophageal cancer [29]. This suggests COX-2 is an important, but not the only VEGF-C upstream regulator in tumor lymphangiogenesis. COX-2 and VEGF-C expression should be examined in the context of other proposed lymphangiogenic molecules such as HIF-1a in further investigation.

\section{Conclusion}

Our study showed that COX-2 and VEGF-C may play an important role in tumor metastasis. COX-2 may be upregulated by VEGF-C expression in order to promote lymphangiogenesis in human breast cancer. It is a considerable speculation that a COX-2 inhibitor prevents lymph node metastasis of breast cancer in clinical use.

\section{Competing interests}

The author(s) declare that they have no competing interests.

\section{Authors' contributions}

$\mathrm{XHZ}$ and DPH designed and interpreted the experiments. DPH performed most of the experiments. GLG and GRC assisted with design/execution of some experiments. HXZ and LW carried out the immunoassays. DPH, SYC and $\mathrm{XHZ}$ wrote the manuscript. All authors read and approved the final the manuscript.

\section{Acknowledgements}

We thank Chang-Lin Zhou for statistical assistance.

\section{References}

I. Stacker SA, Hughes RA, Achen MG: Molecular targeting of lymphatics for therapy. Curr Pharm Des 2004, I (1):65-74.

2. Skobe M, Hawighorst T, Jackson DG, Prevo R, Janes L, Velasco P, Riccardi L, Alitalo K, Claffey K, Detmar M: Induction of tumor lymphangiogenesis by VEGF-C promotes breast cancer metastasis. Nat Med 200I, 7(2): 192-198.

3. Saharinen P, Tammela T, Karkkainen MJ, Alitalo K: Lymphatic vasculature: development, molecular regulation and role in tumor metastasis and inflammation. Trends Immunol 2004, 25(7):387-395.

4. Stacker SA, Achen MG, Jussila L, Baldwin ME, Alitalo K: Lymphangiogenesis and cancer metastasis. Nat Rev Cancer 2002, 2(8):573-583.

5. Rozic JG, Chakraborty C, Lala PK: Cyclooxygenase inhibitors retard murine mammary tumor progression by reducing tumor cell migration, invasiveness and angiogenesis. Int J Cancer 200I, 93(4):497-506.

6. Singh B, Lucci A: Role of cyclooxygenase-2 in breast cancer. J Surg Res 2002, 108(I): 173-179.

7. Zha S, Yegnasubramanian V, Nelson WG, Isaacs WB, De Marzo AM: Cyclooxygenases in cancer: progress and perspective. Cancer Lett 2004, 21 5(I): I-20.

8. Su JL, Shih JY, Yen ML, Jeng YM, Chang CC, Hsieh CY, Wei LH, Yang PC, Kuo ML: Cyclooxygenase-2 induces EPI- and HER-2/Neudependent vascular endothelial growth factor-C up-regulation: a novel mechanism of lymphangiogenesis in lung adenocarcinoma. Cancer Res 2004, 64(2):554-564.

9. Byeon JS, Jung HY, Lee YJ, Lee D, Lee GH, Myung SJ, Yang SK, Hong WS, Kim JH, Min YI, Kim JS: Clinicopathological significance of vascular endothelial growth factor- $C$ and cyclooxygenase-2 in esophageal squamous cell carcinoma. J Gastroenterol Hepatol 2004, 19(6):648-654.

10. von Rahden BH, Stein HJ, Puhringer F, Koch I, Langer R, Piontek G, Siewert JR, Hofler H, Sarbia M: Coexpression of cyclooxygenases (COX-I, COX-2) and vascular endothelial growth factors (VEGF-A, VEGF-C) in esophageal adenocarcinoma. Cancer Res 2005, 65( I 2):5038-5044.

11. Kyzas PA, Stefanou D, Agnantis NJ: COX-2 expression correlates with VEGF-C and lymph node metastases in patients with head and neck squamous cell carcinoma. Mod Pathol 2005, 18(I): $153-160$. 
12. Robbins P, Pinder S, de Klerk N, Dawkins H, Harvey J, Sterrett G, Ellis I, Elston C: Histological grading of breast carcinomas: a study of interobserver agreement. Hum Pathol 1995, 26(8):873-879.

13. Weidner N: Current pathologic methods for measuring intratumoral microvessel density within breast carcinoma and other solid tumors. Breast Cancer Res Treat 1995, 36(2): I69-180.

14. Heimburg S, Oehler MK, Papadopoulos T, Caffier H, Kristen P, Dietl J: Prognostic relevance of the endothelial marker CD 34 in ovarian cancer. Anticancer Res I999, I9(4A):2527-2529.

15. Beasley NJ, Prevo R, Banerji S, Leek RD, Moore J, van Trappen P, Cox G, Harris AL, Jackson DG: Intratumoral lymphangiogenesis and lymph node metastasis in head and neck cancer. Cancer Res 2002, 62(5): | $315-1320$.

16. Costa C, Soares R, Reis-Filho JS, Leitao D, Amendoeira I, Schmitt FC: Cyclo-oxygenase 2 expression is associated with angiogenesis and lymph node metastasis in human breast cancer. J Clin Pathol 2002, 55(6):429-434

17. Choi WW, Lewis MM, Lawson D, Yin-Goen Q, Birdsong GG, Cotsonis GA, Cohen C, Young AN: Angiogenic and lymphangiogenic microvessel density in breast carcinoma: correlation with clinicopathologic parameters and VEGF-family gene expression. Mod Pathol 2005, I 8(I): |43-I52.

18. Kahn HI, Marks A: A new monoclonal antibody, D2-40, for detection of lymphatic invasion in primary tumors. Lab Invest 2002, 82(9): | $255-\mid 257$.

19. Vleugel MM, Bos R, van der Groep P, Greijer AE, Shvarts A, Stel HV, van der Wall E, van Diest PJ: Lack of lymphangiogenesis during breast carcinogenesis. J Clin Pathol 2004, 57(7):746-75I.

20. Schoppmann SF, Bayer G, Aumayr K, Taucher S, Geleff S, Rudas M, Kubista E, Hausmaninger H, Samonigg H, Gnant M, Jakesz R, Horvat $R$ : Prognostic value of lymphangiogenesis and lymphovascular invasion in invasive breast cancer. Ann Surg 2004, 240(2):306-312.

21. Bono $P$, Wasenius VM, Heikkila $P$, Lundin J, Jackson DG, Joensuu $H$ : High LYVE-I-positive lymphatic vessel numbers are associated with poor outcome in breast cancer. Clin Cancer Res 2004, I 0(2 I):7|44-7|49.

22. Padera TP, Kadambi A, di Tomaso E, Carreira CM, Brown EB, Boucher Y, Choi NC, Mathisen D, Wain J, Mark EJ, Munn LL, Jain RK: Lymphatic metastasis in the absence of functional intratumor lymphatics. Science 2002, 296(5574): I883-I886.

23. Pepper MS, Tille JC, Nisato R, Skobe M: Lymphangiogenesis and tumor metastasis. Cell Tissue Res 2003, 3 I4(I):I67-I77.

24. Kinoshita J, Kitamura K, Kabashima A, Saeki H, Tanaka S, Sugimachi $\mathrm{K}$ : Clinical significance of vascular endothelial growth factorC (VEGF-C) in breast cancer. Breast Cancer Res Treat 200I, 66(2): $159-164$.

25. Al-Rawi MA, Mansel RE, jiang WG: Molecular and cellular mechanisms of lymphangiogenesis. Eur J Surg Oncol 2005, 3 I(2): $|17-12|$.

26. Timoshenko AV, Chakraborty C, Wagner GF, Lala PK: COX-2mediated stimulation of the lymphangiogenic factor VEGFC in human breast cancer. Br I Cancer 2006, 94(8): I | 54- I I63.

27. Nakamura $Y$, Yasuoka $H$, Tsujimoto $M$, Yang $Q$, Tsukiyama $A$, Imabun S, Nakahara M, Nakao K, Nakamura M, Mori I, Kakudo K: Clinicopathological significance of vascular endothelial growth factor-C in breast carcinoma with long-term follow-up. Mod Pathol 2003, I6(4):309-314.

28. Half E, Tang XM, Gwyn K, Sahin A, Wathen K, Sinicrope FA: Cyclooxygenase- 2 expression in human breast cancers and adjacent ductal carcinoma in situ. Cancer Res 2002, 62(6): $|676-| 68 \mid$.

29. Katsuta M, Miyashita M, Makino H, Nomura T, Shinji S, Yamashita K, Tajiri T, Kudo M, Ishiwata T, Naito Z: Correlation of hypoxia inducible factor-I alpha with lymphatic metastasis via vascular endothelial growth factor- $C$ in human esophageal cancer. Exp Mol Pathol 2005, 78(2): I23-I30.

\section{Pre-publication history}

The pre-publication history for this paper can be accessed here:

http://www.biomedcentral.com/1471-2407/8/4/prepub
Publish with Biomed Central and every scientist can read your work free of charge

"BioMed Central will be the most significant development for disseminating the results of biomedical research in our lifetime. "

Sir Paul Nurse, Cancer Research UK

Your research papers will be:

- available free of charge to the entire biomedical community

- peer reviewed and published immediately upon acceptance

- cited in PubMed and archived on PubMed Central

- yours - you keep the copyright 